\title{
The Trend of the Distribution of Ectopic Pregnancy Sites and the Clinical Characteristics of Cesarean Scar Pregnancy
}

\author{
Panpan Tang \\ The Third Affiliated Hospital of Sun Yet-sun University \\ Xiaomao Li \\ The Third Affiliated Hospital of Sun Yet-sun University \\ Wenwei Li \\ The Third Affiliated Hospital of Sun Yet-sun University \\ Yunhui Li \\ The Third Affiliated Hospital of Sun Yat-Sen University \\ Yu Zhang \\ The Third Affiliated Hospital of Sun Yet-sun University \\ Yuebo Yang ( $\square$ yueboyang001@163.com) \\ Third Affiliated Hospital of Sun Yat-Sen University https://orcid.org/0000-0002-0257-5313
}

\section{Research}

Keywords: Ectopic pregnancy, Distribution, Trend, Tubal pregnancy, Caesarean scar pregnancy

Posted Date: August 17th, 2021

DOI: https://doi.org/10.21203/rs.3.rs-793776/v1

License: (1) This work is licensed under a Creative Commons Attribution 4.0 International License. Read Full License 


\section{Abstract}

Objective: To investigate the distribution and its variation trend of the ectopic site and the clinical characteristics of cesarean scar pregnancy, to provide clues for further clinical practice.

Methods: 3915 patients are brought into our study. To calculate the distribution of the implantation of ectopic pregnancy. Then analyze with trend $\chi^{2}$ test and calculate the quantity of each type of ectopic pregnancy during the year 2012-2015 and the year 2016-2019 to analyze the variation trend.

Results: 1 . The proportion of each site of ectopic pregnancy is as following: tubal pregnancy ( $84.70 \%)$, ovarian pregnancy $(1.56 \%)$, cesarean scar pregnancy $(8.63 \%)$, abdominal pregnancy $(0.61 \%)$, cornual pregnancy $(2.68 \%)$, cervical pregnancy $(0.49 \%)$, heterotopic pregnancy $(0.43 \%)$. 2. Through trend $\chi^{2}$ test, the ratio of cesarean scar pregnancy to ectopic pregnancy showed an increasing trend $(P=0.005)$. From the year 2012-2015 to the year 2016-2019, the ratio of cesarean scar pregnancy to ectopic pregnancy increased from $5.74 \%$ to $11.81 \%(P<0.001)$. $3.72 .78 \%(246 / 338)$ cesarean scar pregnancy patients had cesarean delivery once, $25.15 \%(85 / 338)$ had cesarean delivery twice, and $2.07 \%$ (7/338) had cesarean delivery three times. $80.18 \%(271 / 338)$ had aborted before. The most common clinical manifestations are amenorrhea (98.52\%), abdominal pain (25.74\%) and vaginal bleeding (67.76\%), the most common sign is hysterauxesis (46.75\%).

Conclusion: As the increasing of the ratio of cesarean scar pregnancy to ectopic pregnancy, the cesarean delivery rate should be decreased to decrease the morbidity of cesarean scar pregnancy.

\section{Plain English Summary}

Ectopic pregnancy happens when fertilized ovum implants outside the endometrium of uterine cavity, which is a life-threatening disease and is an important cause of pregnancy-related mortality. With the increase of pelvic and intrauterine operation, the distribution of ectopic sites has been changing, but the variation has been little studied. In order to have a deep investigation of the distribution of ectopic sites and its variation trend, we collected the data of 3915 ectopic pregnancy cases from the third affiliated hospital of Sun Yat-Sen University.

Through trend $\chi^{2}$ test, the ratio of cesarean scar pregnancy to ectopic pregnancy showed an increasing trend $(P=0.005)$. From the year 20122015 to the year 2016-2019, the ratio of cesarean scar pregnancy to ectopic pregnancy increased from $5.74-11.81 \%(P<0.001)$. As the increasing of the ratio of cesarean scar pregnancy to ectopic pregnancy, the clinical characteristics of cesarean scar pregnancy was analyzed.

$72.78 \%(246 / 338)$ cesarean scar pregnancy patients had cesarean delivery once, $25.15 \%(85 / 338)$ had cesarean delivery twice, and $2.07 \%$ (7/338) had cesarean delivery three times. $80.18 \%(271 / 338)$ had aborted before. The most common clinical manifestations are amenorrhea (98.52\%), abdominal pain (25.74\%) and vaginal bleeding (67.76\%), the most common sign is hysterauxesis (46.75\%).

In conclusion, as the increasing of the ratio of cesarean scar pregnancy to ectopic pregnancy, the cesarean delivery rate should be decreased to decrease the morbidity of cesarean scar pregnancy.

\section{Background}

Ectopic pregnancy happens when fertilized ovum implants outside the endometrium of uterine cavity, which is a life-threatening disease and is an important cause of pregnancy-related mortality ${ }^{[1]}$. Tubal pregnancy is the most common type of ectopic pregnancy. Uncommon types of ectopic pregnancy includes ovarian pregnancy, cervical pregnancy, abdominal pregnancy, cesarean scar pregnancy...

The site of ectopic pregnancy can affect the clinical syndrome, treatment and prognosis of patients. Ovarian pregnancy is more likely to rupture than tubal pregnancy ${ }^{[2]}$. The cesarean scar pregnancy has the possibility of massive hemorrhage and uterine rupture ${ }^{[3]}$. It's important to clarify the site of ectopic pregnancy when we encounter a patient considering ectopic pregnancy, but the distribution of ectopic pregnancy sites has been little studied.

With the increase of pelvic and intrauterine operation, the distribution of ectopic sites has been changing, but the variation has been little studied. In order to have a deep investigation of the distribution of ectopic sites and its variation trend, we collected the data of ectopic pregnancy cases from the third affiliated hospital of Sun Yat-Sen University to analyze the variation trend of ectopic sites.

\section{Materials And Methods}

It's a retrospective descriptive study. We analyzed the data of ectopic pregnancy patients from the year 2011 to the year 2019 from the gynecology department of the third affiliated hospital of Sun Yat-Sen University. During the year 2011 to the year 2019, 3915 ectopic 
pregnancy patients were hospitalized. The sites of ectopic pregnancy were determined by the operating surgeon and pathologists or by ultrasound test. The following sites were included in our study: interstitial pregnancy, isthmic pregnancy, ampullar pregnancy, fimbria pregnancy, ovarian pregnancy, abdominal pregnancy, cervical pregnancy, cesarean scar pregnancy, cornual pregnancy and heterotopic pregnancy.

After calculating the distribution of the implantation of ectopic pregnancy, we compared the trend of the distribution of ectopic pregnancy sites through trend $\chi^{2}$ tests, and divided cases into the year 2012-2015 and the year 2016-2019, analyze the variation trend through $\chi^{2}$ tests. All statistical analyses were carried out with SPSS version 25.

\section{Results}

1. The Sites of Ectopic Pregnancy

Tubal pregnancy consists of $84.70 \%$ of ectopic pregnancy. Because some cases were diagnosed by ultrasound tests, or because the ectopic mass ruptured or aborted, which leads to the difficulty of confirming the ectopic site, we can't figure out the ectopic site of 953 tubal pregnancy cases. Ampullary pregnancy constitutes $89.21 \%$ of tubal pregnancy.

2. The Variations of Sites of Ectopic Pregnancy

Calculate the site of ectopic pregnancy year by year, because the branch hospital was put into use at 2011 , the data of 2011 will not be included.

The proportion of tubal pregnancy show a decreasing trend, the proportion of cesarean scar pregnancy and cornual pregnancy shows an increasing trend.

As the cases of different ectopic pregnancy shows a fluctuant trend, for comparing the trend of the distribution of ectopic pregnancy site better, divide the cases into the year 2012-2015 and the year 2016-2019.

From the year 2012-2015 to the year 2016-2019, the proportion of tubal pregnancy decreased from $90.06-80.98 \%(P<0.001)$, the ratio of cesarean scar pregnancy to ectopic pregnancy increased from $5.74-11.81 \%(P<0.001)$. The ratio of cornual pregnancy, cervical pregnancy and heterotopic pregnancy to ectopic pregnancy all show an increasing trend, but there is only small amount of cornual pregnancy, cervical pregnancy and heterotopic pregnancy cases.

3. The clinical characteristics of cesarean scar pregnancy

As the ratio of cesarean scar pregnancy to ectopic pregnancy shows an increasing trend, the clinical data of cesarean scar pregnancy was collected and analyzed.

The mean age is $32.90 \pm 4.80$ years old, the mean gestational age is $6.67 \pm 1.82$ weeks. $72.78 \%(246 / 338)$ patients had cesarean delivery once, $25.15 \%(85 / 338)$ had cesarean delivery twice, and $2.07 \%(7 / 338)$ had cesarean delivery three times. The most common clinical manifestations are amenorrhea, abdominal pain and vaginal bleeding, the most common sign is hysterauxesis. HCG is almost at the level of $20000-100000$ $\mathrm{U} / \mathrm{L}$, progesterone is almost less than $60 \mathrm{nmol} / \mathrm{L}$. 40.23\%(126/338) patients were treated by suction curettage, 37.28\%(126/338) patients were treated by suction curettage + uterine arterial embolization. Patients were also treated by conservative treatment methods, or other kinds of surgery, like hysteroscope and laparoscope.

\section{Discussions}

The site of ectopic pregnancy can affect the clinical syndrome of patients. Compared with tubal pregnancy, ovarian pregnancy is easier to rupture, which leads to a higher shock rate and needs more emergency management ${ }^{[4]}$. The mortality rate of abdominal pregnancy is eight times higher than tubal pregnancy with a mortality rate of $0.5-18 \%$ as for late diagnosis and treatment ${ }^{[5-6]}$. Having a clear picture of the distribution of ectopic pregnancy can help us make clinical decisions better when we encountered a patient considering ectopic pregnancy.

But the site of ectopic pregnancy has been little studied. Most studies are focusing on the trend of ectopic pregnancy ratio of all female population or focusing on the mortality rate of one specific type of ectopic pregnancy. Tubal pregnancy is the most common type of ectopic pregnancy. According to former studies, about $95 \%$ ectopic pregnancy is tubal pregnancy ${ }^{[7]}$, ovarian pregnancy makes up about $0.5 \%-3 \%$ of ectopic pregnancy with an incidence rate of $1 / 7000-1 / 40,000$ live births ${ }^{[8-10]}$, abdominal pregnancy makes up about $1.3 \%$ with incidence rate ranges from 1 in 10000 to 30000 pregnancies ${ }^{[11-12]}$, cervical pregnancy comprises about $1 \%$ with incidence rate varies between 1 in 2,500 and 1 in 12,422 pregnancies ${ }^{[13-14]}$, while cesarean scar pregnancy makes up about $6 \%$ of ectopic pregnancy with its incidence rate is about 
from 1 in 2500 to 1 in 1800 of pregnancies ${ }^{[15-16]}$. Most studies just focus on a specific type of ectopic pregnancy, and we can only get general information about the ectopic pregnancy distribution. According to our data, tubal pregnancy consists of $84.70 \%$ of ectopic pregnancy, which is lower than the $95 \%$ from former studies. The proportion of ovarian pregnancy, abdominal pregnancy, cervical pregnancy, cesarean scar pregnancy and cornual pregnancy are close to former studies.

According to the study of Bouyer ${ }^{[17]}$ at the year 2001, interstitial pregnancy accounts for $2.4 \%$ of ectopic pregnancy, isthmic pregnancy consists of $12 \%$, ampullary pregnancy accounts for $70 \%$, fimbrial pregnancy makes up $11.1 \%$, ovarian pregnancy accounts for $3.2 \%$ and abdominal pregnancy comprises $1.3 \%$. According to our data, interstitial pregnancy consists of $3.39 \%$, isthmic pregnancy makes up $4.82 \%$, ampullary pregnancy accounts for $89.21 \%$, fimbrial pregnancy accounts for $2.58 \%$.

With the increase of cesarean delivery rate in China, the incidence rate of cesarean scar pregnancy has been increasing during the recent years. Cesarean scar pregnancy is a special type of ectopic pregnancy in which embryo implants at cesarean scar. Cesarean scar pregnancy can lead to severe complications, such as severe hemorrhage and uterine rupture ${ }^{[18]}$. According to the study of Li Hong-Tian ${ }^{[19]}$, during the year 2008-2018, the cesarean delivery rate increased from $28.8-36.7 \%$.

The proportion of tubal pregnancy shows a decreasing trend, the proportion of cesarean scar pregnancy and cornual pregnancy shows an increasing trend. From the year 2012-2015 to the year 2016-2019, the proportion of cesarean scar pregnancy to ectopic pregnancy increased from $5.74-11.81 \%$, which reminds us the cesarean delivery rate should be decreased to decrease the morbidity of cesarean scar pregnancy.

From the year 2012-2015 to the year 2016-2019, the ratio of tubal pregnancy to ectopic pregnancy decreased from $90.06-80.98 \%$. It may be because of the rise of women's health awareness, which leads to the decrease of the rate of pelvic inflammatory disease and tubal diseases. According to the study of Kreisel $\mathrm{K}^{[20]}$, the ratio of emergency department visits due to pelvic inflammatory disease decreased from $0.57 \%$ in 2006 to $0.41 \%$ in 2013. In addition, patients are more willing to treat tubal infertility, which also leads to the decrease of tubal diseases.

The ratio of cornual pregnancy to ectopic pregnancy increased from $1.89-3.58 \%$, which may be related to the increase of intrauterine operation and the damage of endometrium due to intrauterine operation. It's important to decrease the unnecessary intrauterine operation.

Cesarean scar pregnancy means the fertilized ovum implants at the cesarean scar. After implantation, trophocyte can invade into myometrium and grow there, which may lead to uterine rupture or massive bleeding. If keeping growing, cesarean scar pregnancy can develop into placenta previa, placenta implantation and dangerous placenta previa, bringing giant risks to pregnant women ${ }^{[21]}$. Cesarean scar pregnancy is highly related to cesarean delivery history, but the pathogenesis is still unclear, its pathogenesis is maybe the broadening of scar, fibrosis and ischemia of uterine wall, poor healing of scar ${ }^{[22]}$. According to former studies, the high-risk factors of cesarean scar pregnancy are abortion history, multiple cesarean delivery history, the way of suture and the intervals with last cesarean delivery ${ }^{[23]}$. The scar sickness of patients with double-layer suture is thicker than patients with one-layer suture ${ }^{[24]}$. It's in accord with the data at my hospital. $72.78 \%(246 / 338)$ patients had cesarean delivery once, $25.15 \%(85 / 338)$ had cesarean delivery twice, and $2.07 \%(7 / 338)$ had cesarean delivery three times. $80.18 \%(271 / 338)$ had aborted before.

According to the study of So Yun Kim ${ }^{[25]}$, the mean age of cesarean scar pregnancy is $35.7 \pm 3.8$ years old, the mean gestational age at diagnosis is $6.5 \pm 1.1$ weeks and the mean hCG before treatment is 30,785 (range $550-155,356$ ) U/L. According to Lanrong Luo [26], the mean age of cesarean scar pregnancy is $34.16 \pm 4.4$ years old. According to my data, the mean age is $32.90 \pm 4.80$ years old, $67.16 \%(227 / 338)$ patients are between $30 \sim 39$ years old, the mean gestational age is $6.67 \pm 1.82$ weeks, which is close to former study.

The diagnosis of cesarean scar pregnancy is mainly through ultrasound tests, especially transvaginal ultrasound combined with transabdominal ultrasound, Magnetic Resonance Imaging can be used to clarify the relationship between gestation sac and other organs when necessary. Its main clinical manifestations are amenorrhea, abdominal pain and vaginal bleeding [27], like other kinds of ectopic pregnancies. According to my data, the most common clinical manifestations are amenorrhea(98.52\%), abdominal pain(25.74\%) and vaginal bleeding(67.76\%), the most common sign is hysterauxesis(46.75\%).

The main treatment methods of cesarean scar pregnancy are suction curettage, suction curettage + uterine arterial embolization, hysteroscopy, hysteroscopy + uterine arterial embolization and laparoscope. Uterine arterial embolization can highly reduce the possibility of massive hemorrhage. It can also be treated by conservative treatment methods, using methotrexate localized or systematic ${ }^{[28]}$. At my hospital, 40.23\% $(126 / 338)$ patients were treated by suction curettage, 37.28\%(126/338) patients were treated by suction curettage + uterine arterial embolization. Suction curettage and suction curettage + uterine arterial embolization are the dominating treatment methods.

\section{Conclusions}


Tubal pregnancy consists of $84.70 \%$ of ectopic pregnancy, which is lower than the former data. Cesarean scar pregnancy makes up $8.63 \%$ of ectopic pregnancy. the proportion of cesarean scar pregnancy shows an increasing trend. As cesarean scar pregnancy has the possibility of massive hemorrhage and hysterorrhexis, the cesarean delivery rate should be decreased to decrease the morbidity of cesarean scar pregnancy.

Cesarean scar pregnancy is highly related to cesarean delivery history. The most common clinical manifestations are amenorrhea, abdominal pain and vaginal bleeding, the most common sign is hysterauxesis. Cesarean scar pregnancy can be treated by different methods, suction curettage and suction curettage + uterine arterial embolization are the dominating treatment methods at my hospital.

\section{List Of Abbreviations}

Not applicable.

\section{Declarations}

\section{Ethics approval and consent to participate}

The approval was waived.

\section{Consent for publication}

Not applicable.

\section{Availability of data and materials}

The datasets used and analyzed during the current study are available from the corresponding author on reasonable request.

\section{Competing interests}

The authors declare that they have no competing interests.

\section{Funding}

Not applicable.

\section{Authors' contributions}

Panpan tang analyzed data and wrote the manuscript. Xiaomao Li and Wenwei Li were responsible for modifying and editing the manuscript. Yunhui Li and Yu Zhang collected data. Yuebo Yang conducting the research, provided case resources for the research and edited the manuscript. All authors read and approved the final manuscript.

\section{Acknowledgements}

Not applicable.

\section{References}

1. Lisonkova Sarka,Tan Justin,Wen Qi et al. Temporal trends in severe morbidity and mortality associated with ectopic pregnancy requiring hospitalisation in Washington State, USA: a population-based study.[J] .BMJ Open, 2019, 9: e024353.

2. Seo Mi Rang,Choi Joong Sub,Bae Jaeman et al. Preoperative diagnostic clues to ovarian pregnancy: retrospective chart review of women with ovarian and tubal pregnancy.[J]. Obstet Gynecol Sci, 2017, 60: 462-468.

3. Shi Min,Zhang Hui,Qi Sha-Sha et al. Identifying risk factors for cesarean scar pregnancy: a retrospective study of 79 cases.[J] .Ginekol. Pol., 2018, 89: 195-9.

4. Seo Mi Rang,Choi Joong Sub,Bae Jaeman et al. Preoperative diagnostic clues to ovarian pregnancy: retrospective chart review of women with ovarian and tubal pregnancy.[J] .Obstet Gynecol Sci, 2017, 60: 462-468.

5. Poole Aaron,Haas David,Magann Everett F,Early abdominal ectopic pregnancies: a systematic review of the literature.[J] .Gynecol Obstet Invest, 2012, 74: 249-60.

6. Atrash H K,Friede A,Hogue C J,Abdominal pregnancy in the United States: frequency and maternal mortality.[J] .Obstet Gynecol, 1987, 69: 333-7. 
7. Rana P, Kazmi I, Singh R et al. Ectopic pregnancy: A review. [J] Arch Gynecol Obstet 2013, 288: 747-757.

8. Chukus Anjeza,Tirada Nikki,Restrepo Ricardo et al. Uncommon Implantation Sites of Ectopic Pregnancy: Thinking beyond the Complex Adnexal Mass.[J] .Radiographics, 2015, 35: 946-59.

9. Raziel A,Golan A,Pansky M et al. Ovarian pregnancy: a report of twenty cases in one institution.[J] .Am J Obstet Gynecol, 1990, 163: 11825.

10. Selo-Ojeme D 0,GoodFellow C F,Simultaneous intrauterine and ovarian pregnancy following treatment with clomiphene citrate.[J] .Arch Gynecol Obstet, 2002, 266: 232-4.

11. Khan Khalid S,Wojdyla Daniel,Say Lale et al. WHO analysis of causes of maternal death: a systematic review.[J] .Lancet, 2006, 367: 10661074.

12. Cosentino Francesco,Rossitto Cristiano,Turco Luigi Carlo et al. Laparoscopic Management of Abdominal Pregnancy.[J] .J Minim Invasive Gynecol, 2017, 24: 724-725.

13. Shavell Valerie I,Abdallah Mazen E,Zakaria Mark A et al. Misdiagnosis of cervical ectopic pregnancy.[J] .Arch Gynecol Obstet, 2012, 285: 423-6.

14. Ushakov F B,Elchalal U,Aceman P J et al. Cervical pregnancy: past and future.[J] .Obstet Gynecol Surv, 1997, 52: 45-59.

15. Seow K-M,Huang L-W,Lin Y-H et al. Cesarean scar pregnancy: issues in management.[J] .Ultrasound Obstet Gynecol, $2004,23: 247-53$.

16. Wu Chaoying,Li Yong,Ye Wenfeng et al. Cook Cervical Ripening Balloon successfully prevents excessive hemorrhage combined with ultrasound-guided suction curettage in the treatment of cesarean scar pregnancy.[J] .J. Obstet. Gynaecol. Res., $2017,43: 1043-1047$.

17. Bouyer J,Coste J,Fernandez H et al. Sites of ectopic pregnancy: a 10 year population-based study of 1800 cases.[J] .Hum. Reprod., 2002, 17: 3224-30.

18. Liu Dongmei,Yang Min,Wu Qingqing,Application of ultrasonography in the diagnosis and treatment of cesarean scar pregnancy.[J] .Clin. Chim. Acta, 2018, 486: 291-297.

19. Li Hong-Tian,Hellerstein Susan,Zhou Yu-Bo et al. Trends in Cesarean Delivery Rates in China, 2008-2018.[J] .JAMA, 2020, 323: 89-91.

20. Kreisel Kristen,Flagg Elaine W,Torrone Elizabeth,Trends in pelvic inflammatory disease emergency department visits, United States, 20062013.[J] .Am. J. Obstet. Gynecol., 2018, 218: 117.e1-117.e10.

21. Gao Lufen,Huang Zhongwei,Zhang Xian et al. Reproductive outcomes following cesarean scar pregnancy - a case series and review of the literature.[J] .Eur J Obstet Gynecol Reprod Biol, 2016, 200: 102-7.

22. Wang C-B,Chiu W-W-C,Lee C-Y et al. Cesarean scar defect: correlation between Cesarean section number, defect size, clinical symptoms and uterine position.[J] . Ultrasound Obstet Gynecol, 2009, 34: 85-9. $\nabla$

23. Yuan Xiaorui, Kong Hongxia, Chen Yannan etal. Clinical analysis of 53 cesarean scar pregnancy cases[J]. Contemporary Medicine, 2014,20(05):52-53.

24. YU Xiao-chuan. Influence of different suture methods of the lower uterus on the scar thickness and complications of the lower uterus in re-pregnant women [J]. CHINA MODERN MEDICINE ,2021,28(02):94-97.

25. Kim So Yun,Yoon So Ra,Kim Mi Jung et al. Cesarean scar pregnancy; Diagnosis and management between 2003 and 2015 in a single center.[J] .Taiwan J Obstet Gynecol, 2018, 57: 688-691.

26. Luo Lanrong,Ruan Xiangyan,Li Changdong et al. Early clinical features and risk factors for cesarean scar pregnancy: a retrospective casecontrol study.[J] .Gynecol Endocrinol, 2019, 35: 337-341.

27. Luo Lanrong,Ruan Xiangyan,Li Changdong et al. Early clinical features and risk factors for cesarean scar pregnancy: a retrospective casecontrol study.[J] .Gynecol Endocrinol, 2019, 35: 337-341.

28. Grechukhina Olga,Deshmukh Uma,Fan Linda et al. Cesarean Scar Pregnancy, Incidence, and Recurrence: Five-Year Experience at a Single Tertiary Care Referral Center.[J] .Obstet Gynecol, 2018, 132: 1285-1295.

\section{Tables}


Table 1

The ectopic site distribution of 3915 ectopic pregnancy cases

\begin{tabular}{|c|c|c|c|c|c|c|c|c|c|}
\hline Site & $\begin{array}{l}\text { Tubal } \\
\text { pregnancy(n) }\end{array}$ & $\begin{array}{l}\text { Ovarian } \\
\text { pregnancy(n) }\end{array}$ & $\begin{array}{l}\text { Cesarean } \\
\text { scar } \\
\text { pregnancy(n) }\end{array}$ & $\begin{array}{l}\text { Abdominal } \\
\text { pregnancy(n) }\end{array}$ & $\begin{array}{l}\text { Cornual } \\
\text { pregnancy(n) }\end{array}$ & $\begin{array}{l}\text { Cervical } \\
\text { pregnancy(n) }\end{array}$ & $\begin{array}{l}\text { Heterotopic } \\
\text { pregnancy(n) }\end{array}$ & $\begin{array}{l}\text { Other } \\
\text { sites }\end{array}$ & Total \\
\hline $\mathrm{n}$ & 3316 & 61 & 338 & 24 & 105 & 19 & 17 & 35 & 3915 \\
\hline$\%$ & 84.70 & 1.56 & 8.63 & 0.61 & 2.68 & 0.49 & 0.43 & 0.89 & \\
\hline
\end{tabular}

Table 2

Distribution of the sites of tubal pregnancy

\begin{tabular}{|llllll|}
\hline Site & Interstitial pregnancy & Isthmic pregnancy & Ampullar pregnancy & Fimbria pregnancy & Total \\
\hline $\mathrm{n}$ & 80 & 114 & 2108 & 61 & 2363 \\
\hline$\%$ & 3.39 & 4.82 & 89.21 & 2.58 & \\
\hline
\end{tabular}

Table 3

The ectopic site distribution each year

\begin{tabular}{|c|c|c|c|c|}
\hline Year & Tubal pregnancy(n) & Ovarian pregnancy(n) & Cesarean scar pregnancy(n) & Abdominal pregnancy(n) \\
\hline 2012 & $372(91.62 \%)$ & $3(0.74 \%)$ & $22(5.42 \%)$ & $5(1.23 \%)$ \\
\hline 2013 & 383(93.41\%) & $7(1.71 \%)$ & $16(3.90 \%)$ & $0(0.00 \%)$ \\
\hline 2014 & $420(88.61 \%)$ & $6(1.27 \%)$ & $31(6.54 \%)$ & $1(0.21 \%)$ \\
\hline 2015 & $347(86.75 \%)$ & $9(2.25 \%)$ & $28(7.00 \%)$ & $2(0.50 \%)$ \\
\hline 2016 & $414(81.02 \%)$ & $6(1.17 \%)$ & $67(13.11 \%)$ & $2(0.39 \%)$ \\
\hline 2017 & $434(82.51 \%)$ & $5(0.95 \%)$ & $52(9.89 \%)$ & $7(1.33 \%)$ \\
\hline 2018 & $397(80.86 \%)$ & $9(1.83 \%)$ & $59(12.02 \%)$ & $0(0.00 \%)$ \\
\hline 2019 & $339(79.21 \%)$ & $8(1.87 \%)$ & $53(12.38 \%)$ & $6(1.40 \%)$ \\
\hline$P$ & $<0.001$ & 0.704 & 0.005 & 0.826 \\
\hline Year & Cornual pregnancy(n) & Cervical pregnancy(n) & Heterotopic pregnancy(n) & Total \\
\hline 2012 & $3(0.74 \%)$ & $0(0.00 \%)$ & $1(0.25 \%)$ & 406 \\
\hline 2013 & $4(0.98 \%)$ & $0(0.00 \%)$ & $0(0.00 \%)$ & 410 \\
\hline 2014 & $15(3.16 \%)$ & $1(0.21 \%)$ & $0(0.00 \%)$ & 474 \\
\hline 2015 & $10(2.50 \%)$ & $3(0.75 \%)$ & $1(0.25 \%)$ & 400 \\
\hline 2016 & $13(2.54 \%)$ & $5(0.98 \%)$ & $4(0.78 \%)$ & 511 \\
\hline 2017 & 19(3.61\%) & $4(0.76 \%)$ & $5(0.95 \%)$ & 526 \\
\hline 2018 & 18(3.67\%) & $3(0.61 \%)$ & $5(1.02 \%)$ & 491 \\
\hline 2019 & $20(4.67 \%)$ & $1(0.23 \%)$ & $1(0.23 \%)$ & 428 \\
\hline $\mathrm{P}$ & 0.037 & 0.382 & 0.256 & \\
\hline
\end{tabular}


Table 4

The comparison of distribution sites of the year 2012-2015 and the year 2016-2019

\begin{tabular}{|lllll|}
\hline Year & Tubal pregnancy(n) & Ovarian pregnancy(n) & Cesarean scar pregnancy(n) & Abdominal pregnancy(n) \\
\hline $2012-2015$ & $1522(90.06 \%)$ & $25(1.48 \%)$ & $97(5.74 \%)$ & $8(0.47 \%)$ \\
\hline $2016-2019$ & $1584(80.98 \%)$ & $28(1.43 \%)$ & $231(11.81 \%)$ & $15(0.77 \%)$ \\
\hline$P$ & $<0.001$ & 0.506 & $<0.001$ & 0.183 \\
\hline Year & Cornual pregnancy(n) & Cervical pregnancy(n) & Heterotopic pregnancy(n) & Total \\
\hline $2012-2015$ & $32(1.89 \%)$ & $4(0.24 \%)$ & $2(0.12 \%)$ & 1690 \\
\hline $2016-2019$ & $70(3.58 \%)$ & $13(0.66 \%)$ & $15(0.77 \%)$ & 1956 \\
\hline$P$ & $<0.001$ & 0.046 & 0.003 & \\
\hline
\end{tabular}


Table 5

The clinical characteristics of cesarean scar pregnancy

\begin{tabular}{|c|c|c|}
\hline & $n=338$ & $\%$ \\
\hline \multicolumn{3}{|l|}{ Age(y) } \\
\hline$<20$ & 0 & 0.00 \\
\hline $20 \rrbracket 29$ & 81 & 23.96 \\
\hline $30 \rrbracket 39$ & 227 & 67.16 \\
\hline$\geq 40$ & 30 & 8.88 \\
\hline Mean \pm SD & $32.90 \pm 4.80$ & \\
\hline \multicolumn{3}{|l|}{ Gestational age(weeks) } \\
\hline$<6$ & 74 & 23.57 \\
\hline $6 \rrbracket 8$ & 167 & 53.18 \\
\hline$\geq 8$ & 73 & 23.25 \\
\hline Unclear gestational age & 24 & \\
\hline Mean \pm SD & $6.67 \pm 1.82$ & \\
\hline \multicolumn{3}{|l|}{ Gestation history } \\
\hline Childbearing history & 338 & 100.00 \\
\hline Abortion history & 271 & 80.18 \\
\hline Ectopic pregnancy history & 22 & 6.51 \\
\hline Pelvic disease history & 3 & 0.89 \\
\hline Pelvic surgery history (except cesarean delivery) & 28 & 8.28 \\
\hline \multicolumn{3}{|l|}{ Cesarean delivery history } \\
\hline 1 & 246 & 72.78 \\
\hline 2 & 85 & 25.15 \\
\hline 3 & 7 & 2.07 \\
\hline Assisted reproductive history & 3 & 0.89 \\
\hline Birth control history & 8 & 2.37 \\
\hline Intrauterine contraceptive device & 2 & 0.59 \\
\hline Oral contraceptive & 5 & 0.15 \\
\hline Ligation operation & 1 & 0.30 \\
\hline \multicolumn{3}{|l|}{ Clinical manifestations } \\
\hline Amenorrhea & 333 & 98.52 \\
\hline Abdominal pain & 87 & 25.74 \\
\hline Vaginal bleeding & 229 & 67.76 \\
\hline Syncope & 0 & 0.00 \\
\hline Shock & 0 & 0.00 \\
\hline \multicolumn{3}{|l|}{ Signs } \\
\hline Adnexal mass & 6 & 1.78 \\
\hline Adnexal tenderness & 4 & 1.18 \\
\hline
\end{tabular}




\begin{tabular}{|c|c|c|}
\hline & $n=338$ & $\%$ \\
\hline Cervical lifting pain & 9 & 2.66 \\
\hline Hysterauxesis & 158 & 46.75 \\
\hline Aspirating blood during culdocentesis & 0 & 0.00 \\
\hline \multicolumn{3}{|l|}{$\mathrm{HCG}(\mathrm{U} / \mathrm{L})$} \\
\hline $\mathrm{HCG}<20000$ & 100 & 39.06 \\
\hline $20000 \leq \mathrm{HCG}<100000$ & 110 & 42.97 \\
\hline $\mathrm{HCG} \geq 100000$ & 46 & 17.97 \\
\hline Unclear HCG & 112 & \\
\hline \multicolumn{3}{|l|}{ Progesterone(nmol/L) } \\
\hline$P<60$ & 134 & 56.07 \\
\hline $60 \leq P<120$ & 93 & 38.91 \\
\hline$P \geq 120$ & 12 & 5.02 \\
\hline Unclear P & 129 & \\
\hline \multicolumn{3}{|l|}{ Treatment methods } \\
\hline Suction curettage & 136 & 40.23 \\
\hline Suction curettage + uterine arterial embolization & 126 & 37.28 \\
\hline Other surgical treatment methods & 54 & 15.98 \\
\hline Conservative treatment methods & 6 & 1.78 \\
\hline Refuse treatments & 16 & 4.73 \\
\hline
\end{tabular}

